\title{
ON THE SIGNIFICANCE OF SEX HORMONES IN PRODUCING EXPERIMENTAL PROSTATE TUMOR IN THE RAT
}

\author{
MASAHITO HIGUCHI \\ Department of Urology, Kurume University School of Medicine, \\ Kurume, 830, Japan
}

(Received for publication August 1, 1975)

\begin{abstract}
Experimental production of prostate cancer in the animals may contribute to diagnosis and therapy of human prostate cancer by utulizing as a model of provocation, initiation and pathophysiology of the cancer.

It is interesting and important to know in detail the effects of sex hormones on carcinogenic mechanism of prostate cancer which has been supposed to be androgen-dependent. The present author has investigated the influence of sex hormones upon experimental prostate tumor formation, and obtained the following results.

1. In the Donryu rats which have been considered to be vary low in spontaneous tumor formation rate, experiments of tumor formation were performed by direct injection of $1 \% 20-\mathrm{MC}$ or 4 -NQO olive oil solution to the ventral lobe of the prostate and by subcutaneous transplantation of 20-MC or 4-NQO crystal wrapped with the prostate epithelial tissue. In addition, the effects of endocrine milieu on the rate of tumor formation were investigated.

2. The rate of tumor formation was as follows: namely, in the rat group with direct injection of carcinogenic substance to the ventral lobe of the prostate the tumor occurred in $50 \%$ by $20-\mathrm{MC}$ and in $51.3 \%$ by $4-\mathrm{NQO}$ and in the rats with transplantation of wrapped carcinogenic substances the tumor formation rate was $27.8 \%$ by $20-\mathrm{MC}$ and $19.6 \%$ by $4-\mathrm{NQO}$.

The results of the cases associated with change in endocrine milieu could be summarized as follows. In the rat group with direct injection of carcinogenic substances, the rats with castration or with estrogen administration after castration showed higher rate in tumor formation than the rats with only carcinogenic substance, and androgen administration caused reduction in tumor formation rate regardless of methods to produce. In the rat group with transplantation of the wrapped carcinogenic substances, although there was no significant difference in tumor formation rate between the rats with only carcinogenic substance and those with androgen, castration or estrogen administration after castration obviously resulted in an increase in tumor formation rate. However, the tumor formation rate was clearly lower in the female rats with subcutaneous transplantation than in the male rats with the same procedure.

3. The tumors formed experimentally were pathohistologically classified as follows. In the rat group with direct injection, adenoma was seen in 15 $\%$, squamous cell carcinoma in $37.5 \%$, and sarcoma in $47.5 \%$. In the rat group with subcutaneous transplantation, adenoma was observed in $32 \%$,
\end{abstract}


squamous cell carcinoma in $36 \%$, and sarcoma in $32 \%$. Estrogen administration resulted in an evident increase in weight of the tumors formed.

In summary, the present author has failed to provoke experimentally prostate adenocarcinoma which occupies a majority of human prostate cancer.

This, special attention was paid to adenoma formed in the rats. Experimentally produced adenoma was originated from the glandular tissue of the prostate. This type of rat prostate adenoma could be subcutaneously transplanted to the other rats of the same strain. It was attempted to clarify the effects of the change in endocrine milieu on the transplanted adenoma, and the following results were obtained.

1) The rate of successful transplantation was $51.25 \%$ in the male rats and $40.00 \%$ in the female rats.

2) Histological division of the transplanted tumor was done as follows in the male rats: adenoma was seen in $5 \%$, squamous cell carcinoma in $5 \%$, and sarcoma in $5 \%$. Transplanted adenoma tended to alter to malignant one with increasing the time after transplantation.

In the female rats, transplanted adenoma changed to adenocarcinoma in $4 \%$, and the cases of adenoma unchaged were $36 \%$.

3) When endocrine milieu was experimentally changed, the results were summarized. In the rats with hexestrol application after castration, the rate of successful transplantation was $60 \%$ and the rate to provoke adenocarcinoma was $20 \%$. In the female rats, the rate of successful transplantation was $40 \%$ and the rate to provoke adenocarcinoma was $4 \%$. Estrogen dominancy promoted the transition from adenoma to adenocarcinoma.

4) It was actually difficult to decide whether adenoma used was in the precancerous state or not. From experimental results, carcinogenic progress from adenoma to adenocarcinoma was not confirmed. It was presumed that this transition might take place peculiarly and suddenly.

If any exact method to produce carcinoma in certain target organ is established, detailed investigation of possible tumor morphogenesis will be made easily. Its establishment is also really significant because the study of developmental progress of experimental tumors will propose a theory of clinical pathology to provoke human tumors.

Furthermore, establishment of the model of certain experimental tumor not only clarifies pathomorphological development of tumors but contributes analogously to a pathophysiological explanation of human cancers. By these experimental supports, rapid progress will be made possible in the field of early diagnosis and therapy of human cancers.

In the next place, it is also an im- portant problem to establish the method which makes exactly transplanted carcinoma by using the primary tumor focus in the experimental animals.

Figuratively speaking, importance of transplanted carcinoma in experimental tumor study is about the same as that of successive pure cultivated strain of microorganisms in the field of bacteriology. Hence, transplanted carcinoma is a tumor with wide application. In fact, the majority of cancer investigators are using transplanted carcinoma as their materials. It is correct to suppose that, without transplanted carcinoma, present advance in chemotherapy of human cancers might not be made.

There are many reports of experiments of tumor formation in the prostate since the first experiment of 
Moore and Melchiona ${ }^{1)}$ in 1937 who produced squamous cell carcinoma in the prostate by injecting $1: 2$ benzpyrene, one of hydrocarbon compounds, directly into the rat prostate.

As carcinogenic substances to cause experimental prostate tumors, benzpyrene, methylcholanthrene, 4-nitroquinoline-N-oxide, etc. are reported.

Administration methods of these substances are various; Mirand ${ }^{2)}$ and Wojewski ${ }^{3)}$ inserted crystal of carcinogenic substance into the prostate, Moore $^{1)}$, Horning.4), Kälen ${ }^{5)}$, Takenaka 6) and Higuchi ${ }^{7}$ injected solution of carcinogenic substance into the prostate, Dunning ${ }^{8)}$ and Nakanishi ${ }^{91}$ put pellets containing carcinogenic substances in the prostate, and Horning ${ }^{10)}$ adopted a special method in which crystal of 20methylcholanthrene wrapped with the prostate epithelium of the mouse was buried in the subcutaneous region of the other mouse of the same strain.

Pathohistologically, experimentally produced prostate tumors are frequently squamous cell carcinoma in nature. On the contrary, human prostate tumors that urologists encounter actually are usually adenocarcinoma. For these reasons it is extremely dangerous to connect these experimental carcinogenic processes directly to clinical explanation or judgement of human cancer problems. It will be the first theme for tumor investigators to produce experimental adenocarcinoma similar to human prostate adenocarcinoma.

On the other hand, there is an experimental view that androgen acts inhibitorily on proliferation of tumors and estrogen exerts stimulative action on it.

Huggins et al. ${ }^{11)}$ clarified that prostate carcinoma was in nature unusual excess proliferation of the mature prostate epithelium, the proliferation still having features of the epithelium which was an originating matrix tissue. They further experimentally supposed that the abnormal epithelial proliferation tended to present regression or atrophy following castration or administration of estrogen, this fact now being a principal base of the therapy of prostate cancer. It will be also an important problem to clarify the effects of sex hormones on carcinogenic mechanism of prostate cancer which has been supposed to be androgen-dependent.

\section{EXPERIMENTAL MATERIALS AND METHODS}

I. The effects of sex hormones on experimental prostate tumor formation

Experimental materials :

Animals used were the young male and female Donryu rats weighing about $70 \mathrm{~g}$, and experiments were begun at the fifth week after birth. Each rat was fed in each metal cage in the air-conditioned animal room maintained at $24^{\circ} \mathrm{C}$. Animals were fed with CE.2 (a solid feed for rats), and water was given ad libitum.

Carcinogenic substances in this experiment were 20-methylcholanthrene (20-MC) and 4-nitroquinoline- $\mathrm{N}$-oxide (4-NQO), both being manufactured by Wako Pure Chemical Company Ltd. These chemicals were administered in the form of crystal or $1 \%$ olive oil solution.

Sex hormones used were hexestrol (4,4'-dihydroxy- $\alpha, \beta$-diethylbibenzyl disodium phosphate) by Chugai Pharmaceutical Company and testosterone propinate ( $17 \beta$-hydroxyandrost-4-ene-3-one propinate) by Teikoku Zōki Company Ltd. 
Experimental methods :

In the direct injection group, $0.1 \mathrm{ml}$ of $1 \% 20-\mathrm{MC}$ or $4-\mathrm{NQO}$ olive oil solution was directly injected into the ventral lobe of the prostate on the male Donryu rats with a syringe after median scrotal skin section under ether anesthesia.

In the group with an application of 20-MC or 4-NQO crystal, the following procedures were done in turn; namely, the young male Donryu rats elapsed for five weeks after birth were subcutaneously given testosterone propinate in a daily dose of $2.5 \mathrm{mg}$ per a rat for four consecutive days (whole dosage was 10 $\mathrm{mg}$ ), they were sacrificed by bleeding, the ventral lobe of the prostate was aseptically extirpated and its capsule was removed, then prostate parenchymal tissue which was minutely cut to a size of about $2 \mathrm{~mm}^{3}$ was outstretched on the gauze immersed with warm Puck's solution, $0.1 \mathrm{mg}$ of crystal of 20 -MC or 4-NQO was wrapped up with this tissue piece, and finally the wrapped material was inserted to the subcutaneous region of the male and female Donryu rats of the same strain and age.

In the group combined with sex hormone application, $0.5 \mathrm{mg}$ of hexestrol per a rat or $2.5 \mathrm{mg}$ of testosterone propinate per a rat was subcutaneously and continuously injected every day.

The time duration of the experiments was six months for the present, and all the survived rats were killed till the 200 th day after birth. Otherwise, at a suitable time during this period, every one or two rats were sacrificed by bleeding in order to observe the state of tumor formation in combination with parellel performance of weight measuring and tumor palpation. In all animals, observation of angioarchitecture of both the prostate which was directly injected carcinogenic substances and the sub- cutaneous tissue at the site of transplantation, macroscopic examination and weight measure of tumor mass and various organs, and detection of tumor metastasis were made.

Extirpated tumor mass was further transplanted subcutaneously to the male and female rats of the same strain and age after cutting as aseptic as possible. Some of these cut pieces were used for pathologic studies.

Experimental results :

Occurrence of experimental tumor. When the rats which were given $20-\mathrm{MC}$ or 4-NQO as carcinogenic substance were sacrificed or died during the experimental period, the rate of occurrence of experimental tumor could be summarized as follows. In the direct injection group, the rate was 50\% (20 of 40 rats) in $20-\mathrm{MC}$ and $51.3 \%$ (20 of 39 rats) in 4-NQO. In the group with transplantation of wrapped carcinogenic substances, the rate was $27.8 \%$ (15 of 54 rats) in $20-\mathrm{MC}$ and $19.6 \%$ (10 of $51 \mathrm{rats}$ ) in 4 -NQO.

The difference in rate of occurrence of tumor by carcinogenic substance was significant between the cases with 20 $\mathrm{MC}$ and the cases with 4-NQO. As to carcinogenic rate according to administration procedure, the rate of tumor formation after direct injection of carcinogenic substance was evidently higher than that after wrapping carcinogenic crystal with the transplanted tissue.

The rate of tumor formation in the group with direct injection of carcinogenic substances into the prostate was $44.4 \%$ (4 of 9 rats) after 20-MC injection and $40 \%$ (4 of 10 rats) after 4NQO injection. When testosterone propinate was consecutively injected after $20-\mathrm{MC}$ or 4 -NQO application, the rate of tumor formation was $33.3 \%$ (4 or 12 
rats) by the former and $36.3 \%$ (4 of 11 rats) by the latter, the rate being definitely higher in the rats associated with direct injection of carcinogenic substances into the prostate.

When carcinogenic substance was directly injected into the prostate immediately after castration, tumor formation was observed in $60 \%$ (6 of 10 rats) by 20-MC and in $66.6 \%$ (6 of 9 rats) by 4 -NQO. On the contrary, when direct injection of carcinogenic substance immediately after castration was combined with continuous administration of hexestrol, tumor formation rate was $66.6 \%$ (6 of 9 rats) by $20-\mathrm{MC}$ and $66.6 \%$ (6 of 9 rats) by 4 -NQO. There was no significant difference between the cases with only castration and the cases with estrogen application after castration. In summary, the rate of experimental tumor occurrence was clearly higher in the rat group with castration or with estrogen administration after castration, in addition to carcinogenic substance, than in the rat group with only carcinogenic substance. Androgen administration resulted in the decrease in rate of tumor formation (Table 1, A and B).

When carcinogenic substances wrapped with transplanted prostate tissue pieces were subcutaneously inserted to the rats, tumor formation rate in those rats was $27.2 \%$ (3 of 11 rats) by $20-\mathrm{MC}$ and $11.2 \%$ (1 of 9 rats) by 4 -NQO.

When testosterone propinate was injected to the rats with subcutaneous transplantation, tumor formation rate was $25 \%$ ( 2 of 8 rats) in the cases with $20-\mathrm{MC}$ and $9.1 \%$ (1 of 11 rats) in the cases with 4-NQO. Androgen administration did not cause any significant effects on tumor formation rate.

Tumor formation rate was increased in the rats with transplantation after castration; in detail, the rate was 33.3 $\%$ (3 of 9 rats) in $20-\mathrm{MC}$ and $37.5 \%$ (3 of 8 rats) in 4 -NQO. In the rat group with injection of hexestrol after castration, there was significant difference in tumor formation rate between $20-\mathrm{MC}$ (50\%, 6 of 12 rats) and $4-\mathrm{NQO}$ (33.3\%, 4 of 12 rats).

When carcinogenic substance wrapped by transplanted prostate tissue pieces was further transplanted subcutaneously to the female rats, tumor was occurred in $7.1 \%$ ( 1 of 14 rats) by $20-\mathrm{MC}$ and in $9.1 \%$ ( 1 of 11 rats) by 4-NQO.

In the rate of tumor formation following transplantation of carcinogenic substances by wrapping up with prostate tissue pieces, androgen caused no significant change in the rate, while castration or estrogen application with castration significantly increased the rate. However, tumor formation rate was lower in the female rats with transplantation than in the male rats with the same procedure (Table $2, \mathrm{~A}$ and $\mathrm{B}$ ).

On pathologic findings. First, angioarchitecture was examined. In the rats with injection of carcinogenic substances into the ventral lobe of the prostate, early change was new building of the blood vessels in the prostate capsule which was supposed to be a living reaction to foreign substances. In these cases, the grade of the fresh vascular production became marked in parallel to advance of the tumor formation. Its detailed pattern could not be investigated because of adhesion to nearby organs. In an early stage of the experiments of tumor formation by transplantation, transplanted tissue pieces capable of passing through the carcinogenic substances did not show new building of the blood vessels but were frequently changing to necrotic masses. New or further building of the vascular vessels became marked with increasing the size of tumor mass. 
TABLE 1-A

Occurrence of experimental tumor: 20-methylcholanthrene was directly injected into the prostate

\begin{tabular}{|c|c|c|c|c|c|c|c|c|c|}
\hline \multirow[b]{2}{*}{ Group A } & \multirow[b]{2}{*}{ Experimental method } & \multirow[b]{2}{*}{ Rats No. } & \multirow{2}{*}{$\begin{array}{l}\text { Rats No. } \\
\text { of tumor }\end{array}$} & \multirow{2}{*}{$\left|\begin{array}{c}\text { Occurrence } \\
\text { of tumor } \\
(\%)\end{array}\right|$} & \multicolumn{4}{|c|}{ Tumors } & \multirow[b]{2}{*}{ Remarks column } \\
\hline & & & & & $\begin{array}{l}\text { Adeno- } \\
\text { carcinoma }\end{array}$ & Adenoma & $\begin{array}{l}\text { Squamous } \\
\text { cell } \\
\text { carcinoma }\end{array}$ & Sarcoma & \\
\hline Group I & 20-methylcholanthrene & 9 & 4 & 44.4 & & & 1 & 3 & Pneumonia 1 \\
\hline Group II & $\begin{array}{l}20-\mathrm{MC} \text { and } \\
\text { testosterone propinate }\end{array}$ & 12 & 4 & 33.3 & & 1 & 1 & 2 & $\begin{array}{l}\text { Stone of the bladder } 1 \\
\text { Pneumonia } 2\end{array}$ \\
\hline Group III & 20-MC and castration & 10 & 6 & 60.0 & & 1 & 2 & 3 & $\begin{array}{l}\text { Stone of the bladder } 1 \\
\text { Hydronephrosis } 1\end{array}$ \\
\hline Group IV & $\begin{array}{l}20-\mathrm{MC} \text {, castration } \\
\text { and hexestrol }\end{array}$ & 9 & 6 & 66.6 & & 1 & 3 & 2 & Hydronephrosis 2 \\
\hline
\end{tabular}

TABLE 1-B

Occurrence of experimental tumor: 4-nitroquinoline-N-oxide was directly injected into the prostate

\begin{tabular}{|c|c|c|c|c|c|c|c|c|c|}
\hline \multirow[b]{2}{*}{ Group A } & \multirow[b]{2}{*}{ Experimental method } & \multirow[b]{2}{*}{ Rats No. } & \multirow{2}{*}{$\mid \begin{array}{l}\text { Rats No. } \\
\text { of tumor }\end{array}$} & \multirow{2}{*}{$\begin{array}{c}\text { Occurrence } \\
\text { of tumor } \\
(\%)\end{array}$} & \multicolumn{4}{|c|}{ Tumors } & \multirow[b]{2}{*}{ Remarks column } \\
\hline & & & & & $\begin{array}{l}\text { Adeno- } \\
\text { carcinoma }\end{array}$ & Adenoma & \begin{tabular}{|l}
$\begin{array}{l}\text { Squamous } \\
\text { cell } \\
\text { carcinoma }\end{array}$ \\
\end{tabular} & Sarcoma & \\
\hline Group V & $\begin{array}{l}\text { 4-nitroquinoline- } \\
\mathrm{N} \text {-oxide }\end{array}$ & 10 & 4 & 40.0 & & & 1 & 3 & $\begin{array}{l}\text { Metastasis of the } \\
\text { bladder } 1 \\
\text { Hematuria } 1 \\
\end{array}$ \\
\hline Group VI & $\begin{array}{l}\text { 4-NQO and } \\
\text { testosterone propinate }\end{array}$ & 11 & 4 & 36.3 & & 1 & 2 & 1 & $\begin{array}{l}\text { Stone of the bladder } 1 \\
\text { Hydronephrosis } 1\end{array}$ \\
\hline Group VII & 4-NQO and castration & 9 & 6 & 66.6 & & 1 & 2 & 3 & $\begin{array}{l}\text { Stone of the bladder } 2 \\
\text { Hematuria } 1\end{array}$ \\
\hline Group VIII & $\begin{array}{l}\text { 4-NQO, castration } \\
\text { and hexestrol }\end{array}$ & 9 & 6 & 66.6 & & 1 & 3 & 2 & $\begin{array}{l}\text { Metastasis of the } \\
\text { lymphonode } 1 \\
\text { Pneumonia } 1\end{array}$ \\
\hline
\end{tabular}


TABLE 2-A

Occurrence of the experimental tumor: 20-methylcholanthrene wrapped with

transplanted prostate tissue pieces were subcutaneously inserted to the rat

\begin{tabular}{|c|c|c|c|c|c|c|c|c|c|}
\hline \multirow[b]{2}{*}{ Group B } & \multirow[b]{2}{*}{ Experimental method } & \multirow[b]{2}{*}{ Rats No. } & \multirow{2}{*}{$\begin{array}{l}\text { Rats No. } \\
\text { of tumor }\end{array}$} & \multirow{2}{*}{$\begin{array}{c}\text { Occurrence } \\
\text { of tumor } \\
(\%)\end{array} \mid$} & \multicolumn{4}{|c|}{ Tumors } & \multirow{2}{*}{$\begin{array}{l}\text { Remarks } \\
\text { column }\end{array}$} \\
\hline & & & & & $\begin{array}{l}\text { Adeno- } \\
\text { carcinoma }\end{array}$ & Adenoma & $\begin{array}{l}\text { Squamous } \\
\text { cell } \\
\text { carcinoma }\end{array}$ & Sarcoma & \\
\hline Group I & 20-methylcholanthrene & 11 & 3 & $27 \cdot 2$ & & 1 & 1 & 1 & \\
\hline Group II & $\begin{array}{l}20-\mathrm{MC} \text { and } \\
\text { testosterone propinate }\end{array}$ & 8 & 2 & 25.0 & & & 2 & & Pneumonia 1 \\
\hline Group III & $20-M C$ and castration & 9 & 3 & 33.3 & & 1 & 1 & 1 & \\
\hline Group IV & $\begin{array}{l}20-\mathrm{MC} \text {, castration } \\
\text { and hexestrol }\end{array}$ & 12 & 6 & 50.0 & & 3 & 2 & 1 & \\
\hline Group V & $20-\mathrm{MC}$ and female rat & 14 & 1 & 7.1 & & & & 1 & \\
\hline
\end{tabular}

TABLE 2-B

Occurrence of experimental tumor: 4-nitroquinoline-N-oxide wrapped with transplanted prostate tissues pieces were subcutaneously inserted to the rat

\begin{tabular}{|c|c|c|c|c|c|c|c|c|c|}
\hline \multirow[b]{2}{*}{ Group B } & \multirow[b]{2}{*}{ Experimental method } & \multirow[b]{2}{*}{ Rats No. } & \multirow{2}{*}{$\begin{array}{l}\text { Rats No. } \\
\text { of tumor }\end{array}$} & \multirow{2}{*}{$\begin{array}{c}\text { Occurrence } \\
\text { of tumor } \\
(\%)\end{array} \mid$} & \multicolumn{4}{|c|}{ Tumors } & \multirow{2}{*}{$\begin{array}{l}\text { Remarks } \\
\text { column }\end{array}$} \\
\hline & & & & & $\begin{array}{l}\text { Adeno- } \\
\text { carcinoma }\end{array}$ & Adenoma & $\begin{array}{l}\text { Squamous } \\
\text { cell } \\
\text { carcinoma }\end{array}$ & Sarcoma & \\
\hline Group VI & $\begin{array}{l}\text { 4-nitroquinoline- } \\
\mathrm{N} \text {-oxide }\end{array}$ & 9 & 1 & 11.2 & & & 1 & & \\
\hline Group VII & $\begin{array}{l}\text { 4-NQO and } \\
\text { testosterone propinate }\end{array}$ & 11 & 1 & 9.1 & & & & 1 & \\
\hline Group VIII & 4-NQO and castration & 8 & 3 & 37.5 & & 1 & 1 & 1 & \\
\hline Group IX & $\begin{array}{l}\text { 4-NQO, castration } \\
\text { and hexestrol }\end{array}$ & 12 & 4 & 33.3 & & 1 & 1 & 2 & . \\
\hline Group X & 4-NQO and female rat & 11 & 1 & 9.1 & & 1 & & & \\
\hline
\end{tabular}


Macroscopic examination of the rats with direct injection of carcinogenic substances indicated that formation of the tumor of various sizes was recognized at the site corresponding to the site of injection and sometimes the tumor became such a large mass as an infant fist, thus occupying the whole abdominal cavity (Fig. 1).

When tumor was occurred by transplanting the wrapped carcinogenic substances, the site of tumor was identical to the site of transplantation. The size of the tumor thus formed was also various and irregular, as in the tumors of the rat group with direct injection. The transplanted tumors were characterized by strong adhesion to the subcutaneous or muscular layer of the abdominal wall (Fig. 2).

These tumor masses were multiform in histologic features. Among 40 rats in which tumors were happened by direct injection of carcinogenic substances, adenoma was observed in 6 rats (15\%), squamous cell carcinoma in 15 rats $(37.5 \%)$ and sarcoma in 19 rats $(47.5 \%)$. In 25 rats with tumor formation following transplantation, adenoma was seen in 8 rats $(32 \%)$, squamous cell carcinoma in 9 rats (36\%), and sarcoma in 8 rats $(32 \%)$.

Weights of the formed tumors ranged from 0.324 to $12.31 \mathrm{~g}$ ( (mean $\pm \mathrm{S}$. D. was $4.547 \pm 1.238 \mathrm{~g}$ ) in the rat group with direct injection of carcinogenic substance into the prostate, and also ranged from 0.238 to $3.872 \mathrm{~g}$ (mean \pm S. D. was $0.934 \pm 0.279 \mathrm{~g}$ ) in the rat group with transplantation of carcinogenic substances wrapped with the prostate epithelial tissue.

When the change in endocrine environment was additionally combined with the following respective conditions, the tumor weight was from 0.379 to $8.271 \mathrm{~g}(4.327 \pm 0.719 \mathrm{~g})$ in the rat group with direct injection of carcinogenic

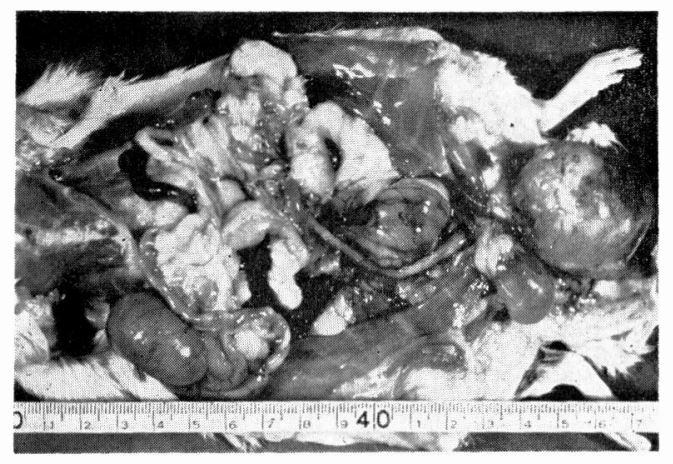

Fig. 1 The rat with direct injection of carcinogenic substance that formation of the various sizes.

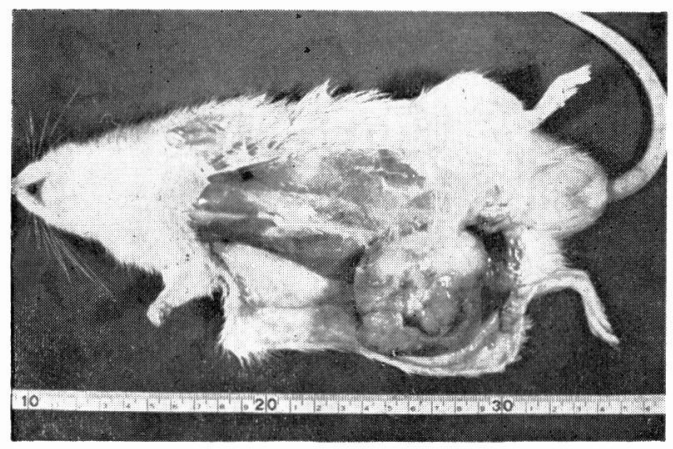

Fig. 2 The tumor was occurred by transplanting the wrapped carcinogenic substances, the site of tumor was identical to the site of transplantation.

substances, from 0.324 to $8.777 \mathrm{~g}$ (4.446 $\pm 0.811 \mathrm{~g})$ in the rat group with androgen administration, from 0.783 to 12.31 $\mathrm{g} \cdot(5.891 \pm 1.121 \mathrm{~g})$ in the rat group with estrogen administration, or from 0.831 to $9.712 \mathrm{~g} \cdot(4.001 \pm 1.212 \mathrm{~g})$ in the group with castration. In the classification of the rats with direct injection of carcinogenic substances, the tumor weights ranged from $0.342 \pm 1.244 \mathrm{~g}(0.721 \pm 0.031$ g) in the group with only carcinogenic substances, from 0.238 to $1.231 \mathrm{~g}$ ( 0.741 $\pm 0.130 \mathrm{~g}$ ) in the group with castration, from 0.742 to $3.872 \mathrm{~g}(2.093 \pm 0.271 \mathrm{~g})$ in 
the group with estrogen administration, or from 0.241 to $0.274 \mathrm{~g}$ in the group with transplantation to the female rats. Tumor weights were evidently increased by estrogen application.

On complications and metastasis. In the group with direct injection of carcinogenic substances into the prostate, the most frequently observable complication was stream disturbance in the urinary tract following an increase in tumor size, and the less frequent or rare complications were hydronephrosis, ureter hydrops, retentive bladder and its sequential bladder stone, and hematuria due to tumor. In the early stage of the experiments, pneumonia was sometimes observed.

Metastasis to various organs took place. Metastasis to the pelvic lymph nodes and metastatic infiltration to the vesical wall were seen in all the rats of the group with injection of 4-NQO. No remote metastasis was recognized.

On the contrary, in the rat group with transplantation of wrapped carcinogenic substances, only one rat died of pneumonia in the early stage of the experiments, and no metastasis was noticed.

In the group with sex hormone administration, the detailed examination of the cardiovascular system was combined, but no special change was observed.

On histogenesis. The normal structure of the ventral lobe of the rat prostate was the glandular tissue which was covered by the single, high-columnar epithelium. When glandular secretion was poor, many papillary extrusions toward the lumen were observed. The cell locating at the basis of the highcolumnar epithelium had a relatively large nucleus and its cytoplasm was basophilic. When the glandular lumen was filled with secretion which was stained lightly with eosin, the glandular internal space looked like a simple cyst, the epithelium reduced its height or size as a flat or dice-like pattern, and the basophilic stainability of the cytoplasm tended to decrease. The glandular parenchymal portion was formed with a few lobules, and development of the interstitial tissues between them was poor (Figs. 3 and 4).

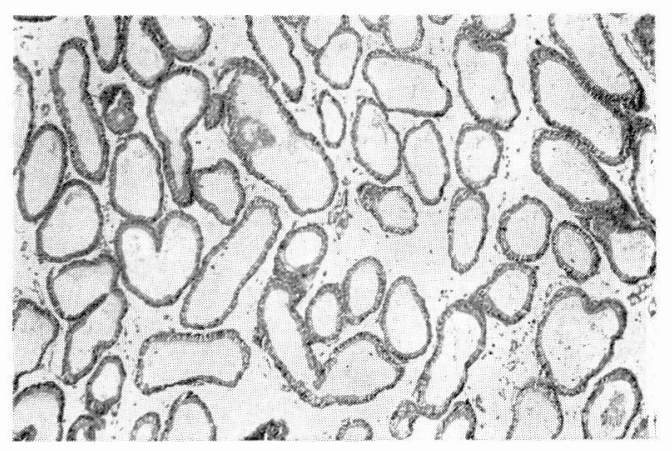

Fig. 3 The normal structure of the ventral lobe of the rat prostate.

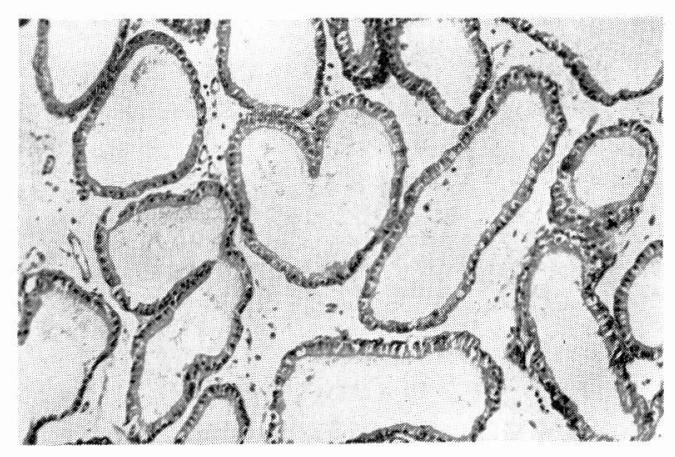

Fig. 4 Magnification of Fig. 3.

The pathohistologic reaction of the prostate tissue to which carcinogenic substances were directly injected was successively followed up. First, tissue destruction at the site of injection was locally observed. A type of inflammation began to take place by reacting 
to carcinogenic substances which were foreign. Then, granuloma was formed by involving carcinogenic crystal. Directly near the granuloma, giant cells for foreign bodies were seen. In the surrounding of the granuloma, infiltration of the round cells and proliferation of fibrogranular cells were recognized. Sometimes there was abscess formation. At that time, the glandular portion adjacent to the site of injection was cystically expanded frequently in association with epithelial destruction or necrotic alteration.

The pathohistologic changes of the prostate tissue which was given wrapped carcinogenic substances were also successively traced. The region in contact to the wrapped material showed remarkable destruction of the tissue, and, near this region, inflammatory process to foreig $n$ body began to take place. Next, infiltration of the giant cells to foreign body appeared in parallel with granuloma formation.

In the tumor showing transition to squamous cell carcinoma, planoepithelial metaplasia of the epithelium appeared at about 100th day. Then, the glandular epithelium was morphologically impressed and became flat. The greater part of the glandular internal spaces was filled with secretion showing dark tone of eosin and with fallen epithelial fragments. Thus, the glandular epithelium began to show hyperplastic tendency, changed to the squamous epithelium with multilayer and marked cornification, and presented partial infiltration to the interstitial tissues (Fig. 5). In this way, squamous cell cancer focus characterized both by almost complete loss of the glandular structure and hyperplasia of the cornic epidermal and prickle cell layer, and by strong cornifying tendency was definitely established (Fig. 6).

In the cases of which artificial tumor

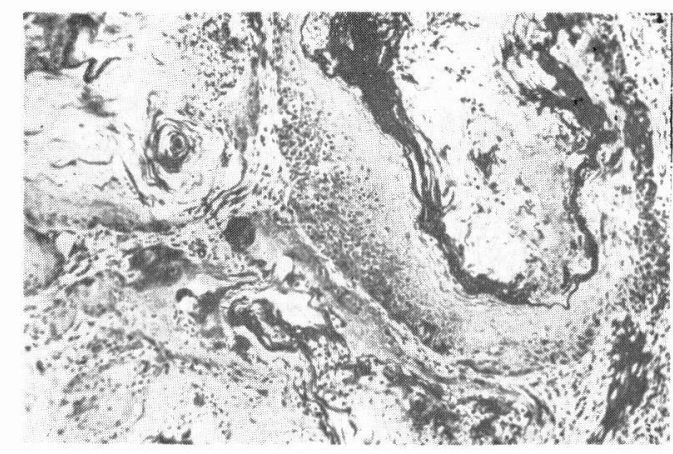

Fig. 5 The tumor showing transition to squamous cell carcinoma, planoepithelial metaplasia of the epithelium.

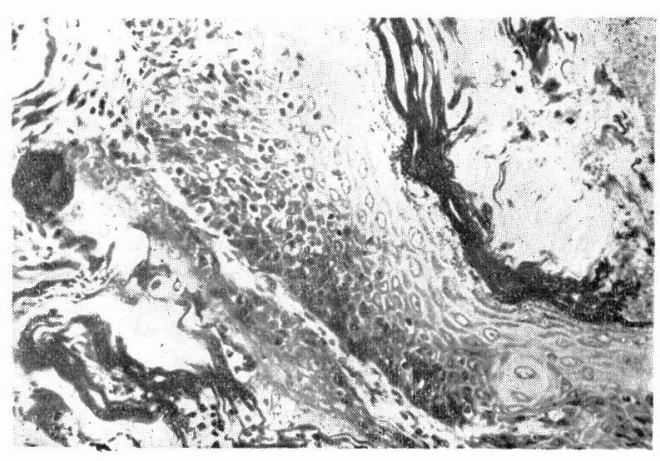

Fig. 6 Magnification of Fig. 5.

was changed to sarcoma, its transition took place suddenly, indicating extremely rapid proliferation of the tumor tissue. Histologically, all the sarcomas thus transformed were leiomyosarcoma. The sarcoma was composed of almost oval cells of which cellular somata were long and slender and their cellular bundles mixed in confusion each other. This leiomyosarcoma was different from leiomyoma in that in the former the cellular component was abundant, the cell size was irregular and unequal, and necrotic pattern was found here and there. The site of mitosis was directly associated with the presence of the griant cells and the mitotic cells were highly atypical (Figs. 7, 8 and 9). 


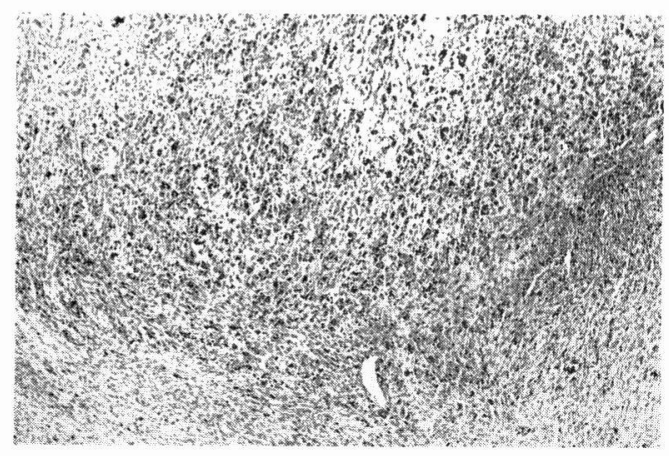

Fig. 7 Sarcoma was composed of almost oval cells of which cellular somata were long and slender their cellular bundles mixed in confusion each other.

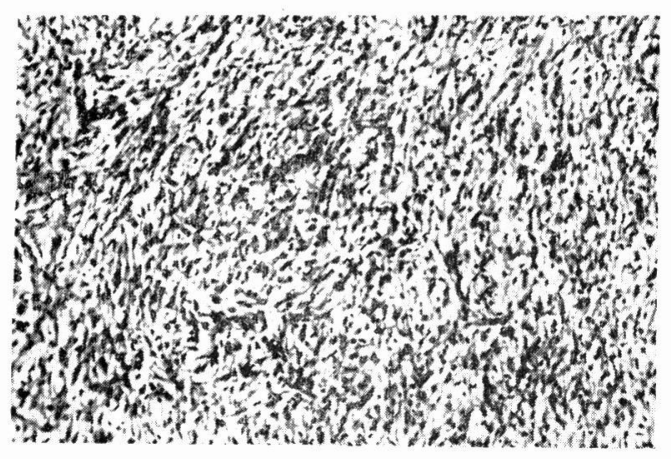

Fig. 8 Magnification of Fig. 7.

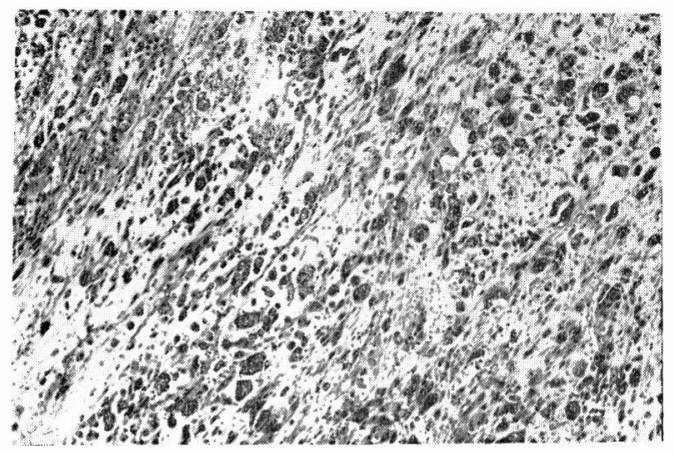

Fig. 9 Magnification of Fig. 7.

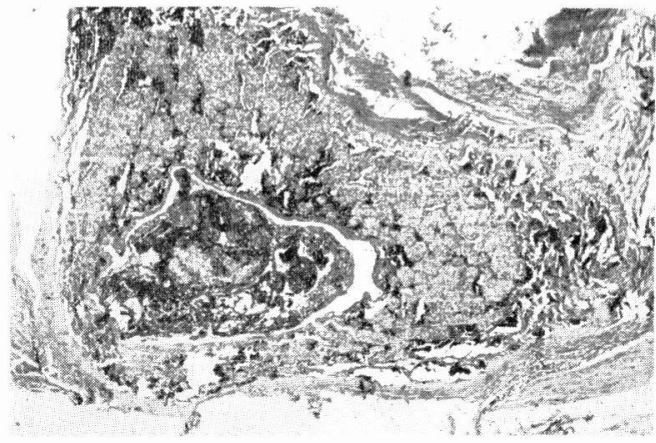

Fig. 10 In the cases of artificial tumor which changed to adenoma, there were the epithelial cells around the crystal.

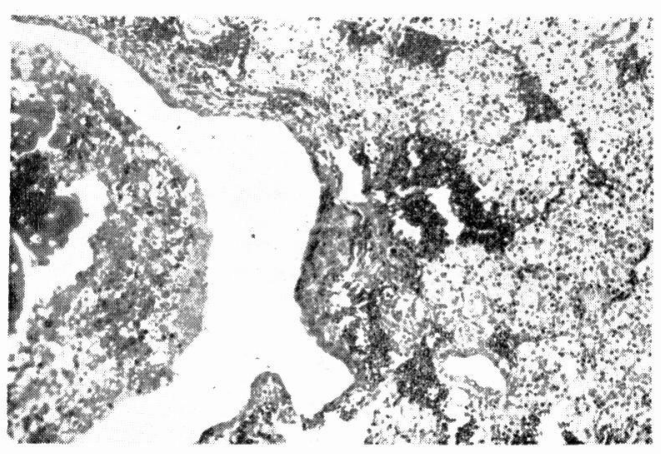

Fig. 11 The structure of the acinus was not observed in the proliferated cell population, the septum composed of the connective tissues disappeared, and the blood vessels, in detail, sinuses were filled with erythrocytes.

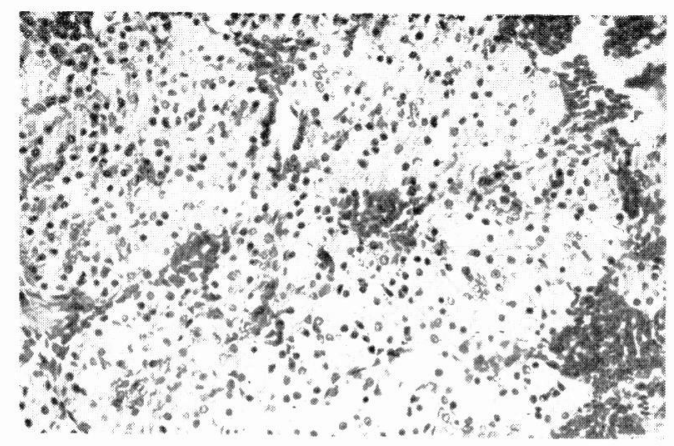

Fig. 12 In this type of adenoma, the cell arrangement was properly irregular and the cells were not typical in nature. 
In the cases of artificial tumor which changed to adenoma, there were the epithelial cells around the crystal applied, the structure of the acinus was not observed in the proliferated cell population, the septum composed of the connective tissues disappeared, and the blood vessels, in detail, sinuses were filled with erythrocytes. In this type of adenoma, the cell arrangement was properly irregular and the cells were not typical in nature (Fig:s. 10, 11 and 12). Near the cells, there were blood vessels expanded by filling up with erythrocytes. Acinar multiplication was marked, and in addition each acinar population was separated by fine connective tissues. One acinus was composed of 5 to 8cells and the nuclei of the cells located at the nuclear peripheral region with equal sizes. Sometimes, vascular degeneration was noticed (Fig. 13).

The change in endocrine circumstances did not specially result in histologic alteration.

II. The effects of the change in endocrine milieu on transplantation of experimentally formed prostate adenoma

Experimental materials:

The tissue for transplantation was made as follows. After injection of 20$\mathrm{MC}$ or $4-\mathrm{NQO}$, the ventral lobe of the prostate was extirpated in a suitable time, and outstretched. Carcinogenic substances were further wrapped with it and the tissue mass was transplanted to another rat. Otherwise, artificial tumor mass detected in a relatively early stage was extirpated. Carcinogenic substances, if retained, were taken away on a gauze immersed with Puck's solution with using a magnifying glass. Some of the removed tissue were histologically examined, and some of the

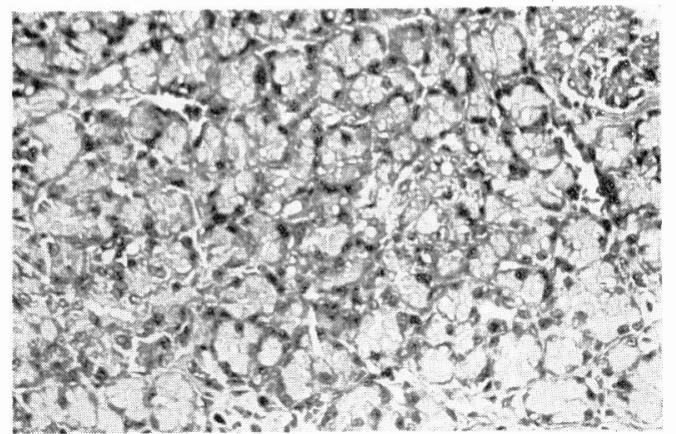

Fig. 13 On acinus was composed of 5 to 8 cells and the nuclei of the cells located at the nuclear peripheral region with equal sizes. Sometimes, vascular degeneration was noticed.

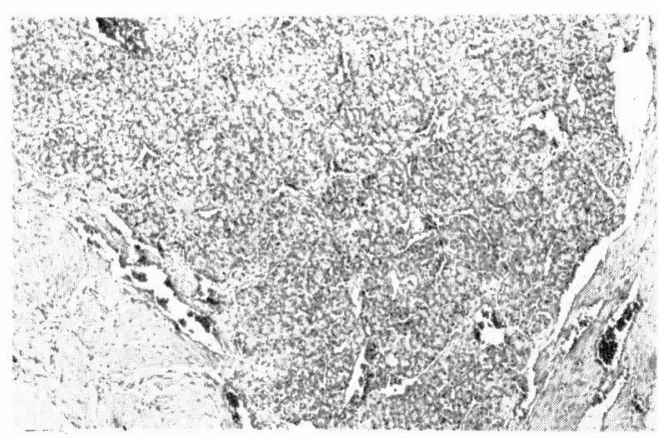

Fig. 14 Adenoma of the tissue for transplantation.

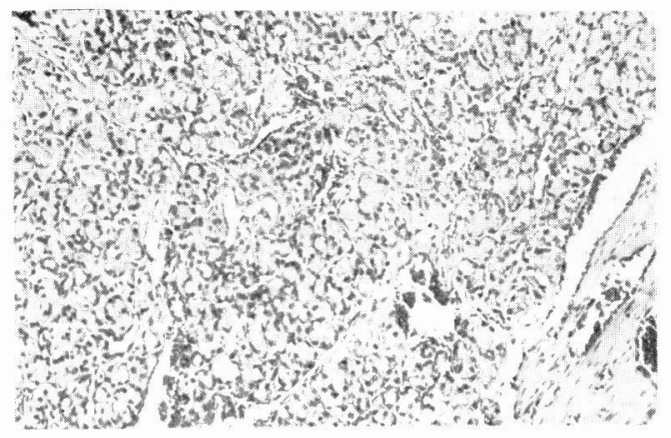

Fig. 15 Adenoma, magnification of Fig. 14 .

tissue pieces which had demonstrated adenoma were selected for transplantation (Figs. 14 and 15). 
Experimental methods :

Some pieces of adenoma tissue thus obtained were transplanted subcutaneously to the young male and female Donryu rats at the fifth week after birth as aseptic as possible. The rats were classified into five experimental groups in order to observe the effects of the change in internal endocrine milieu. The first group was a group of the male rats without any treatments, the second was the rat group with the injection of testosterone propinate in the rate of $2.5 \mathrm{mg}$ per a rat every day, the third was the male rat group with castration, the fourth was the rat group with the injection of hexestrol in a rate of $0.5 \mathrm{mg}$ per a rat every day after castration, and the fifth was the female rat group. Experimental term and observation items were similar to those described above.

\section{Experimental results :}

On the rate of successful transplantation. The rate of success in transplantation was $51.25 \%$ (41 of 80 rats) in the male rats.

Pathohistological changes of transplanted tumors were as follows; adenocarcinoma was $5 \%$ (4 of 80 rats), squamous cell carcinoma $5 \%$ (4 rats), sarcoma $5 \%$ (4 rats), adenoma unchanged $36.25 \%$ (29 rats), necrotic alteration $46.25 \%$ (37 rats) and death $2.5 \%$ (2 rats).

In the examination of 32 rats at the end of the 15 th experimental week, adenoma unchanged was seen in $37.5 \%$ (12 rats), necrosis in $56.25 \%$ (18 rats) and death in $6.25 \%$ (2 rats).

In the survey of 48 rats survived for more than 15 weeks of experimental period, adenocarcinoma was seen in 8.33 $\%$ (4 rats), squamous cell carcinoma in $8.33 \%$ (4 rats), adenoma unchanged in
$35.42 \%$ (17 rats) and necrosis in 35.58 $\%$ (19 rats).

There was a significant difference between these two types of observations. The results suggested that transplanted adenoma tended to become malignant one with increasing the lapse after transplantation.

The rate of successful transplantation was $40 \%$ (10 of 25 rats) in the female rats.

Pathohistologically, adenocarcinoma was $4 \%$ (1 rat), adenoma unchanged $36 \%$ (9 rats), necrotic alteration $52 \%$ (13 rats) and death $8 \%$ (2 rats). Necrotic alteration of the transplanted mass was observed in 7 rats till the 15 th week and 6 rats after the 15th week. Among these tumors, transplanted adenoma without any additional change could be remained for a period longer than 15 weeks.

The effects of the change in internal endocrine milieu on transplantation. In the male 20 rats, the rate of successful transplantation was $55.0 \%$ and the rate to provoke adenocarcinoma from adenoma was $0 \%$. In 20 rats with the injection of testosterone propinate, the rate of successful transplantation was reduced to $40 \%$ as compared to the above figure, but the rate to provoke adenocarcinoma was similarly $0 \%$.

In 20 rats with castration, the rate of successful transplantation was 45.0 $\%$ and the rate to provoke adenocarcinoma was $0 \%$.

In 20 rats with hexestrol injection after castration, the rate of successful transplantation was increased to $65 \%$ and the rate to provoke adenocarcinoma was also increased to such high value as $20 \%$.

On the contrary, in the female 25 rats the rate of succesful transplantaiion was $40 \%$ and the rate to provoke adenocarcinoma was $4 \%$ (Fig. 16). 
Fig. 16 The effects of the change in endocrine milieu on transplantation of experimentally formed prostate adenoma.

- : Adenocarcinoma $\circ:$ Adenoma

$\triangle$ : Squamous cell carcinoma $\triangle$ : Sarcoma

$x:$ Necrosis $\square:$ Death

1. Male rats

The rate of successful transplantation $11 / 20(55.0 \%)$

The rate to provoke adenocarcinoma $0 / 11(0 \%)$

\begin{tabular}{rrrr}
$8 \times 8$ & $\times$ \\
\hline
\end{tabular}

2. Male rats injected testosterone propinate $2.5 \mathrm{mg}$ every day

The rate of successful transplantation $8 / 20(40.0 \%)$

The rate to provoke adenocarcinoma $0 / 8(0 \%)$

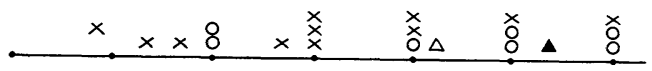

3. Castration of male rats

The rate of successful transplantation $9 / 20(45.0 \%)$

The rate to provoke adenocarcinoma $0 / 9(0 \%)$

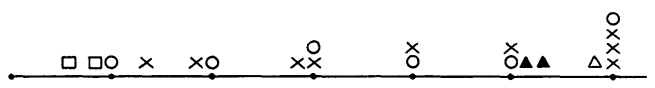

4. Castration of male rats injected hexestrol $0.5 \mathrm{mg}$ every day

The rate of successful transplantation $13 / 20(65.0 \%)$

The rate to provoke adenocarcinoma $4 / 13(30.7 \%)$

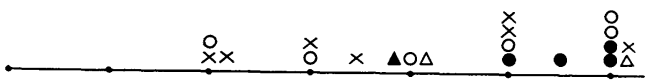

5. Female rats

The rate of successful transplantation $10 / 25(40.0 \%)$

The rate to provoke adenocarcinoma $1 / 10(10.0 \%)$

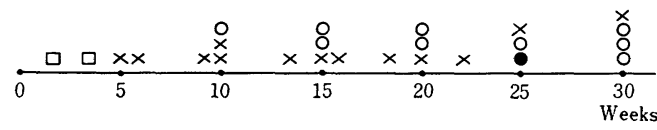

The rate of adenoma which was throughout left as adenoma in the whole course of the experiments will give a suggestion to the effects of internal endocrine milieu on artificial tumors. This rate was $42.5 \%$ (17 of 40 rats) in the male rats or the rats with testosterone propinate, $30 \%$ (12 of 40 rats) in the rats after castration or the rats with hexestrol after castration, and finally $36 \%$ (9 of $25 \mathrm{rats}$ ) in the female rats. In summary, these results indicated that castration and hexestrol injection after castration in the male rats reduced the ability of maintenance of adenoma itself with sequential tendency to malignancy; in other words, the ability to maintain the property of adenoma tended to decline.

On histogenesis. Pathohistological changes of transplanted adenoma were successively followed up. Necrotic alteration, regardless of procedures, was seen in $46.25 \%$. This change might result from necrotic change of the transplanted tissue itself, inflammation to foreign transplanted tissue and incomplete angioarchitecture in the surrounding of the transplanted tissue.

The mechanism to develop squamous cell carcinoma or sarcoma from transplanted adenoma may not be explained by the change in adenoma itself due to endocrine environmental deviation but may be interpreted by a supposition that carcinogenic substances remaining in the transplanted adenoma in a fashion of attachment cause cancer or sarcoma by stimulating the tissue through certain way which is now not yet known in detail (Figs. 17 and 18).

In all rat groups, the transplanted adenoma tissue which was kept without specific pathological change in fine structure was recognized.

The transitional progress from transplanted adenoma to adenocarcinoma 


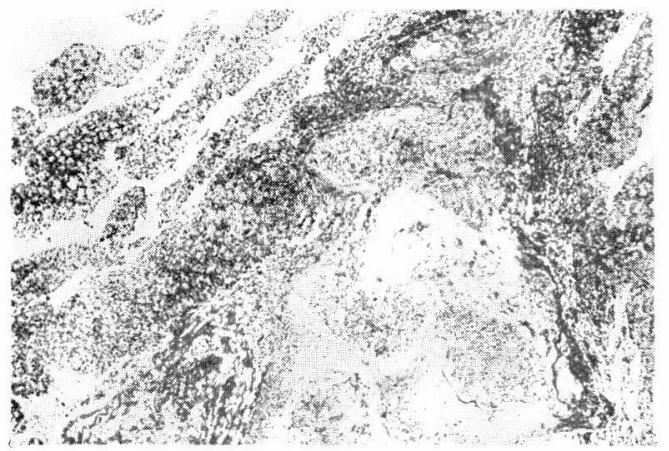

Fig. 17 Squamous cell carcinoma from transplanted adenoma.

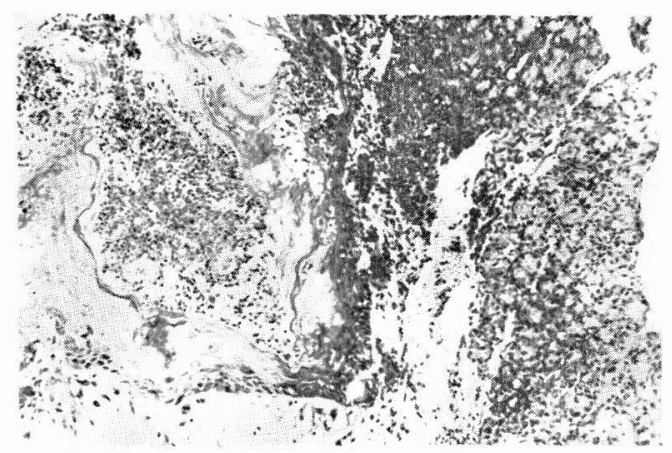

Fig. 18 Magnification of Fig. 17.

could not be actually observed. It is my impression that when the transplanted tumor mass is extirpated and examined after suitable periods it has already turned into adenocarcinoma especially in the cases presenting a change to adenocarcinoma.

The pathological pictures of transplanted tumors were various, and in general little tumors particularly had a relatively well differentiated glandular structure. The cancer cells were usually characterized by low columnar or cubic epithelial pattern, and the intercellular boundary was evident. However, tone of the cytoplasm of the cancer cells was either dark or light (Figs. 19 and 20). Some of adenocarci-

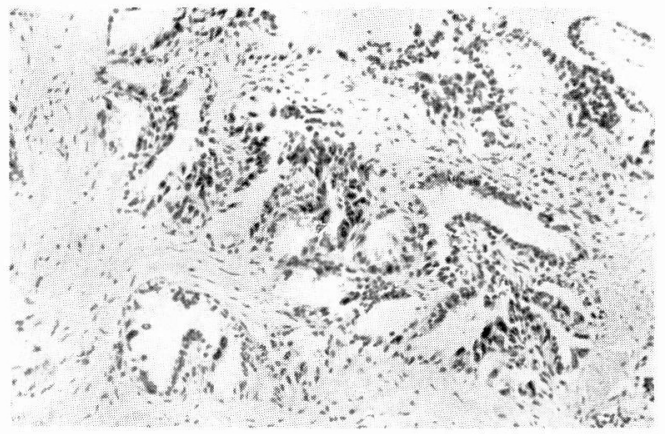

Fig. 19 Adenocarcinoma on castration of male rat injected hexestrol $0.5 \mathrm{mg}$ every day.

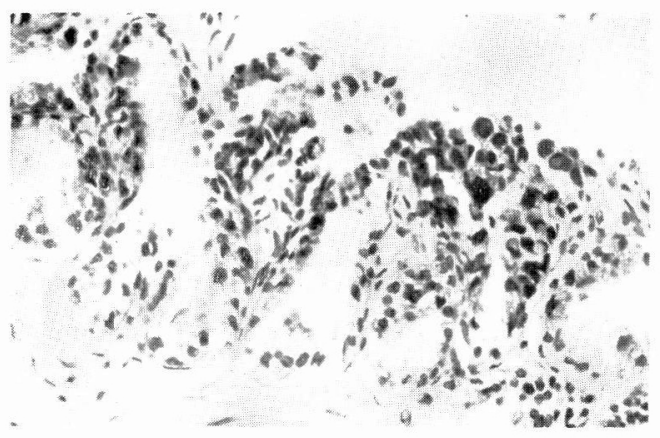

Fig. 20 Magnification of Fig. 19.

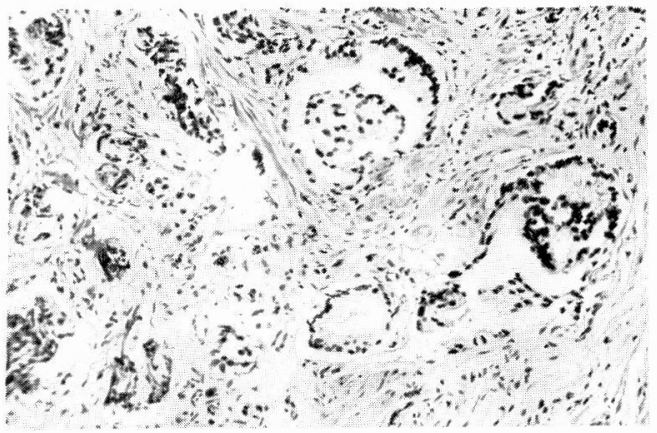

Fig. 21 Adenocarcinoma on castration of male rat injected hexestrol $0.5 \mathrm{mg}$ every day.

noma had a specific property of papillary proliferation (Fig. 21). Another type of adenocarcinoma showed marked 
cancerous infiltration to the interstitial tissue, so that the adenocarcinoma was in an acinar form which demonstrated small lacunar spaces (Figs. 22 and 23).

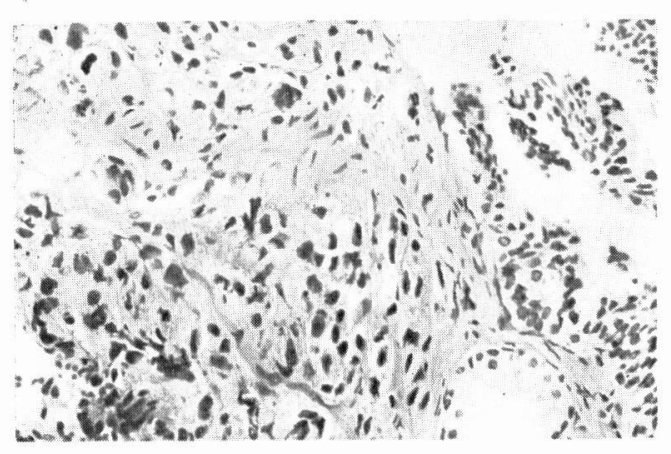

Fig. 22 Magnification of Fig. 21.

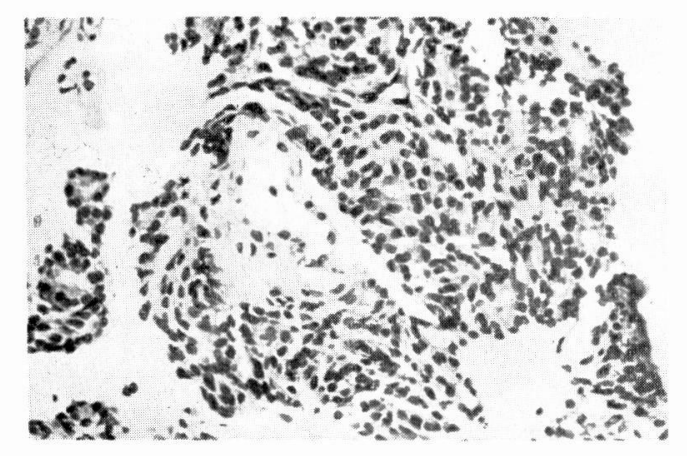

Fig. 23 Adenocarcinoma on female rat.

\section{DISCUSSION}

When any neoplasm can be produced by administering certain substance to experimental animals with adequate procedure, the substance can be designated as a carcinogenic substance.

Investigation of carcinogenic substance shas been made splendidly, and carcinogenic mechanism has also been discussed chemically. At the present time, the number of the substance supposed to be carcinogenic is some hundred thousands, including synthetized chemicals. All of them, however, are non- physiological in nature and do not practically exist in the living body. Even though cancer is simply brought about experimentally in animals or humans by these substances, it is unauthentic to consider that all of naturally occurred cancer are produced by carcinogenic chemicals.

Referring a fact that clinically the frequency of cancer occurrence elevates with increasing the age, it is hypothetically thought that administration of carcinogenic substance causes metabolism disorder similar to that observable as an aging phenomenon and certain by product unexpectedly formed through normal metabolic pathway may contribute to advancement of carcinogenic process. This kind of possibility has been proposed by some investigators. In 1933, Cook et al. ${ }^{12}$ early supposed that abnormal metabolic process of steroids in vivo produced a carcinogenic hydrocarbon compound. In the next 1934, Cook et al. ${ }^{13)}$ and Cook et al. ${ }^{12)}$ succeeded in synthesis of 20-MC from desoxycholic acid. Then, many experiments were done on carcinogenic ability of $20-\mathrm{MC}$ which beared a striking resemblane to dibenzanthracene or benzpyrene of hydrocarbon compound. It is interesting that these compounds can be synthetized from a substance similar to steroids which are normally present in the body. For these reasons, it is correct to suppose that these substances are liable to cause cancer spontaneously by bringing about abnormal metabolic processes similar to delicate reactions in the living organism.

20-MC, a powerful carcinogenic chemical, has made tumor study possible in various fields, but the experiments of prostate tumor formation by using $20-\mathrm{MC}$ are relatively few in number and only basic in stage.

20-MC was artificially synthetized by Ochiai ${ }^{14)}$ in 1943 and was shown to be 
carcinogenic by Nakahara ${ }^{\text {(5) }}$ in 1957 or to be locally carcinogenic by Mori ${ }^{16)}$ in 1961. 4-NQO has been thought to have a particular carcinogenic capability by which tumor is formed in distant regions. The present author attempted to provoke experimental prostate tumor by using these $20-\mathrm{MC}$ and 4 -NQO.

In my experiments of injection of carcinogenic substance to the ventral lobe of the prostate, experimental prostate tumor was formed in $50 \%$ by 20 $\mathrm{MC}$ and in $51.3 \%$ by 4 -NQO. These rates were lower than $78 \%$ which was tumor formation rate obtained by Moore ${ }^{1)}$ after application of benzpyrene to rats, higher than $35 \%$ by Mirand ${ }^{2)}$, and equivalent to $50 \%$ by Dunning ${ }^{8)}$ and $53.9 \%$ by Takenaka ${ }^{6)}$.

In my results of transplantation experiments using wrapped carcinogenic substance, tumor formation rate was $27.8 \%$ by $20-\mathrm{MC}$ and $19.6 \%$ by $4-\mathrm{NQO}$ and the values were lower than $40 \%$ by 20 -MC in Horning' experiment ${ }^{10}$.

In carcinogenic experiments, besides the property of carcinogenic substance, special attention should be paid to such other various factors as dosage, nature of solvent, administration method, duration for use, strain and age of experimental animals, and feeding condition. In particular, when tumor formation experiments are performed by requiring a long term, presence of new additional parameters should be considered. Pure line animal such as $\mathrm{C}_{3} \mathrm{H}$ mouse which zoologically show shigh tumor formation rate is favourable for breast cancer or liver cancer, but no paper is reported as to animals for prostate tumor experiments.

Horning et al. ${ }^{18)}$ gave 20 -MC to two sorts of mice ; tumor incidence was 37.8 $\%$ in mice of strong A strain and 47.5 $\%$ in mice of RIII strain. Takenaka ${ }^{6}$ produced tumor in $53.9 \%$ of the rats of Wistar strain. The present author obtained a similar rate in the rats of Donryu strain. All these values indicate that when experimental conditions are almost identical to each other, many experiments will give the similar results. The results of Källen et al. ${ }^{5}$ are interesting that tumor incidence is low in the rats and the young mice are adequate to tumor formation. These facts should be taken into consideration since human prostate carcinoma is supposed to be one of aging phenomena. The present author has utilized the young rats in his experiments because the prostate is a hormone-sensitive organ and so juvenile animals are thought to be favourable for this purpose.

Up to the present time, sufficient or excess dosage of relatively powerful carcinogenic substance has been applied for exact formation of tumors, however, Arthur et al. ${ }^{19)}$ have proposed a concept of carcinogenic threshold concentration above which tumor formation occurs in all cases. Severi et al. ${ }^{20}$ have stated that an increase in carcinogenic substance applied resulted in shortening of latency and elevation of tumor formation rate. For explanation of delicate carcinogenic mechanism, it is a natural requirement to decide minimum effective dose of carcinogenic substance to present tissue reaction. Matake et al. ${ }^{21)}$ emphasized that, because higher concentrations of carcinogenic substances caused necrosis and sequentially reduced cancer formation rates, not only dosage but concentration might be related to carcinogenicity. In my results, experimental cancer formation rate was much higher in the method of injection of carcinogenic substance dissolved with olive oil than in a technique of direct contact with the cells. The former procedure will permit easy permeation into the tissue and longer affection on the cells. 
In many carcinogenic experiments, most of the formed carcinomata were squamous cell carcinoma in nature. Horning ${ }^{10)}$ developed such a clever procedure as homogeneous subcutaneous transplantation of the prostate epithelial tissue. He experimentally noticed that homogeneously and subcutaneously transplanted prostate epithelial tissues acted to stimulate locally the cellular vital activity which, for example, had been reduced because of the existence within the resting stadium of the secretory phase. He also stated that this transplantation caused histologically splitting of the nucleus or karyoconcentration in the low columnar cells which were locating in the relatively basic portion of the acinus.

Haddow ${ }^{22}$ supposed a decrease in cellular activity or vitality as a background field in which carcinogenic substance behaved to transform or change the normal metabolic reactions in unknown specific manner. Vasiliev et al. ${ }^{23}$ observed tumors originated from the injured cells. Hiegers et al. ${ }^{24}$ reported that tumor occurred from the somatic cells through mutation. Orr 25) 26) also hypothetically discussed that, although intermediate form between normal and tumor cells could not be recognized, tumor cells might be occurred by losing normal metabolic regulation after qualitative change in metabolic, nutrititive and supporting tissues by carcinogenic substance.

The present author introduced a new method to transplant homogeneously and subcutaneously the prostate tissue by imitating the Horning's original method. My modification consisted of wrapping up of carcinogenic substance with extirpated, finely cut, outstretched but injured tissue. These original and modified procedures, as indicated by Orr, brought about (1) various changes of supporting or nutritive tissues at the site of subcutaneous insertion, (2) change of vascular architecture, and (3) qualitative change in cellular metabolic process by insertion into the tissue.

Huggins et al. ${ }^{11}$ concluded that prostate cancer was abnormal proliferation of the mature prostate epithelium with original histologic properties of the prostate epitheilum, and furthermore castration or estrogen administration caused regressive atrophy of prostate cancer. The present day therapy of prostate cancer by hormone application is stood on these facts.

The cell activity of prostate cancer is dependent upon the grade of secretion of androgen, and so tumor cell growth stops when androgen supply is interrupted by castration. Clinically too, it is generally accepted that growth of prostate tumor is inhibited by castration or estrogen administration while exacerbation of prostate cancer takes place by application of androgen. It is expected that estrogen alleviates pain of human prostate cancer. Sex hormones may be related to normal growth of the prostate, and dysharmonic state of the hormones is probably connected to prostate tumor formation.

Practically, when androgen which is thought to be a stimulative factor for prostate tumor is injected, hypertrophy and hyperfunction of the male sexual or accessory sexual organs are widely observed, but tumor formation is not noticed 27) 28) 29).

Thus, the present author tried to perform experiments in order to know what kinds of effects on tumor formation in the rat prostate appeared under abnormal sex hormone milieu. In the group with injection of carcinogenic substance into the prostate, castration and estrogen administration caused tumor formation in higher rates. In the group with administration of androgen, 
the tumor formation rate was reduced.

In the rat group given carcinogenic substance by wrapping with the prostate tissue, estrogen application resulted in an increase in tumor formation rate. Transplantation to the female rats showed lower tumor formation rate than that to the male rats. The increase in tumor formation rate was statistically significant in the rat group with estrogen administration.

In general, prostate tumor which is androgen-dependent occurs in higher rate and becomes worse further when estrogen has been additionally applied. Estrogen administration or estrogen dominancy which is expected in the experimental rats with castration and in the female rats somewhat inhibits tumor formation.

In summarizing the results of many investigators, Dunning et al. ${ }^{8)}$ reported that proliferation of transplanted prostate tumor by 20 -MC was more marked in the female rats than in the male rats, Horning ${ }^{17)}$ observed that estrogen administration facilitated carcinoma formation, and Takenaka ${ }^{6}$ proposed an estrogen dominancy hypothesis.

On the other hand, Moore et al. ${ }^{1)}$ got experimental results that the time of occurrence of experimental tumor was hastened by castration but incidence of the occurrence was reduced by it while combination of castration and androgen administration resulted in an increase in tumor formation. Wojewski et al. ${ }^{30}$ also stated that castration promoted carcinogenicity in the prostate by 20-MC whereas estrogen as well as androgen gave no special effect on tumor formation.

There is no definite conclusion on carcinogenesis by hormone. Röhl ${ }^{27)}$ obtained an interesting conclusion, by summarizing his experiments on the effects of various hormones on tissuecultured prostate cancer tissue, that although the effects of hormones were dependent upon the grade of differentiation of cancer cells, mature prostate cancer was androgen-dependent but immature cancer was not.

It is undoubtful that there is delicate regulatory process of hormone reception at certain sites of the prostate cells or prostate carcinoma cells. It will be the next problem to answer the question that by what mechanism or how the sensitivity of these sites is changed after transplanting the prostate epithelial tissue.

When steroid hormone is given to animals, the hormone raises specific reactions in the cells after passing through the cell membrane of the target organ. This process is explained by hormone-gene theory. This theory now interprets the effects of sex hormones in a manner as follows. Estrogen presents its physiological action in the uterus cells without receiving any metabolic alteration, while testosterone obviously gives androgenic action by combining dihydrotestosterone changed by $5 \alpha$-reductase with the nucleus. In the prostate where is a target organ of androgen, testosterone demonstrates its specific action through reduction from testosterone to dihydrotestosterone in the prostate. Farnsworth ${ }^{31)}$ and Shida et al. ${ }^{32)}$ suppose that estrogen produces direct therapeutic anti-androgenic effects on the prostate cell itself by inhibiting the activity of $5 \alpha$-reductase.

In detail, at the time of testosterone injection to the rats, testosterone may show androgenic influence after changing to dihydrotestosterone. This kind of change is difficult to happen at the time of transplantation of the prostate epithelial tissue to the rats because entry of testosterone is trouble some for a reason of incomplete angioarchitecture and in addition testosterone once entered is hard to become dihydro- 
testosterone sequentially due to qualitative cellular change of the prostate. Accordingly, the effects of androgen on prostate cancer cannot be interpreted by a target organ concept.

Estrogen, when it has entered into the cell, inhibits the activity of $5 \alpha$ reductase and therefore inhibits the action of androgen on the prostate. In the experimental rats with estrogen injection, there may be estrogen advantage endocrinologically.

As discussed above, the effects of sex hormones on development and production of tumor tissue are not fixed. Female sex hormone as well as male sex hormone may play a role not as initiative factor but as accelerative factor. Although the mechanism is not minutely clarified, it is reasonable to suppose that sex hormones play accessory or secondary role for carcinogenicity in coexistence with carcinogenic substances.

Therefore, all of prostate cancers are not androgen-dependent. It is impossible to conclude or designate an initiating factor for prostate cancer probably because the prostate at that time is qualitatively different from the normal prostate especially in its fine structure. As far as the present results are concerned, dysfunctions of endocrine system including unbalance of sex hormones may offer a condition favourable for carcinogenesis. Promotion of tumor formation under a condition of estrogen dominancy indicates that estrogen and androgen behave through the same mechanism.

The experiments in which endocrine medium was changed in association either with direct injection of $20-\mathrm{MC}$ and $4-\mathrm{NQO}$ or with wrapping them with the prostate epithelium demonstrated that histology of the tumors formed had no immediate correlation to carcinogenic substances. In the group with direct injection to the prostate, adenoma was seen in $7.5 \%$, squamous cell carcinoma in $18.98 \%$, and sarcoma in $24.04 \%$, and in the group of wrapping, adenoma was seen in $7.59 \%$, squamous cell carcinoma in $8.57 \%$, and sarcoma in $7.61 \%$, the formation of clinically frequently observable adenocarcinoma being impossible.

Experimentally, adenocarcinoma was formed in 2 of 30 tumors by Mirand ${ }^{2)}$, in 1 of 6 tumors by Källen, and in 11 of 12 tumors following wrapped carcinogenic substances by Horning ${ }^{10}$. The majority of carcinoma reported was squamous cell carcinoma, and sarcoma ranked second.

The present author paid special attention to the formed adenoma composed of the glandular tissue of the prostate. Actual purpose was to form adenocarcinoma by transplanting the adenoma thus produced and changing endocrine milieu. Only the adenoma of which cellular origin could be confirmed as the prostate tissue was used for transplantation. Really used adenoma was not adenoma in the cases following direct injection but adenoma in the cases following wrapping up. The latter tissue specimen was naturally small in size, but carcinogenic crystal remained in the central region of this specimen. Therefore, experiments were made as follows; adenoma portion far distant from central crystal was cut off, crystal was washed out as clean as possible, and the tissue piece was subcutaneously transplanted to the rats of which internal endocrine milieu was artificially changed. The results were the following; a greater part of the transplanted tissues were necrotic, some of them were left as adenoma, transplantable tumor in the male rats was seen in $9.75 \%$ ( 4 of 41 rats), and the same type of tumor in the female rats was observed in $10 \%$ ( 1 of 10 rats).

Such androgen dominancy as the 
male rats and androgen administration did not provoke adenocarcinoma from adenoma, whereas such estrogen dominancy as the female rats and estrogen administration after castration provoked adenocarcinoma.

Whether the tumor used by the present author was completely adenoma or not and whether the tumor was in a precancerous state or not were possible objections. Transformation from adenoma to adenocarcinoma was not so frequent, but the change to carcinoma occurred quite suddenly, and elapsed irreversibly.

Many pathologists including Willis ${ }^{33)}$ thought that carcinogenic process was characterized by preceeding graded focal change requiring a relatively long period, and its ultimate change was malignant tumor ${ }^{34)}$. They suggested the presence of precancerous stage. Rous ${ }^{36)}$, however, explained carcinogenesis in terms of mutation of the latent cells capable of forming carcinoma.

Another concept of carcinogenesis of prostate carcinoma of which specificity is an increase in incidence with aging: is that this carcinoma is a manifestation of aging phenomena as previously proposed by Thiersch, Cohnheim, etc. Considering a fact that prostate carcinoma is frequently originated from the glandular tissue showing senile atrophy, it is likely that the cancer is brought about by mutation of the cells of which vital activity has been physiologically decreased, and at that time the presence of latent cancer promoting factor is hypothetically thought.

Although my experimental results do not approach to the final stage of the investigations of human tumor formation, they will give a clue of the problem of prostate carcinogenesis.

However, if further efforts would be made standing on the clinical basis that there is the case of prostate cancer which is uneffective to such hormone therapy as anti-androgen treatment through castration, significance of sex hormones in producing human prostate cancer will be certainly increased.

\section{REFERENCES}

1) Moore,R.A. and Melchionna,R.H. : Production of tumors of prostate of white rat with 1:2-benzpyrene. Am. J. Cancer, 30, 731-741, 1937.

2) Mirand, E. A.: Prostatic neoplasms in rats. Exp. Med. Surg., 14, 318-331, 1956.

3) Wojewski, A.: The evalution of methods applied in diagnosis of prostatic cancer. Urol. Int., 14, 140-159, 1962.

4) HoRning, E.S. : Local action of 20-methylcholanthrene and sex hormones on prostatic grafts. Brit. J. Cancer, 6, 80-88, 1952.

5 ) KäLleN, B. and RÖHL, L. : Tissue culture studies on a rat prostatic cancer induced with 20-methylcholanthrene. Acta Path. Microbiol. Scand., 50, 283-290, 1960.

6 ) Takenaka, I. : Experimental studies of prostatic tumors. Acta Urol. Jap., 10, 745-758, 1964.

7 ) Higuchi, M., Uemura, K., Eto, K., Gohara, S. and Hirata, S.: Occurrence and ultrastructure of experimentally produced tumors in rat prostates. Kurume Med. J., 19, 205-219, 1972.

8 ) Dunning, W. F, Curtis, M. R. and SegaLOFF, A.: Methylcholanthrene squamous cell carcinoma of the rat prostate with skeletal metastases, and failure of the rat liver to respond to the carcinogen. Cancer Res., 6, 256-262, 1946.

9) NAKANishi, K.: Tumorogenic action of 4nitroquinoline-1-oxide on the prostate of rats. Jap. J. Urol, 62, 838-857, 1971.

10) HoRning, E. S. : Induction of glandular carcinomas of the prostate in the mouse. Lancet, 2, 829-830, 1946.

11) (1) Huggins, C. : Endocrine factors in cancer. J. Urol., 68, 875-884, 1952.

(2) Huggins, C.: Biological activities of steroids in relation to cancer. 1, 1960, New York.

(3) Huggins, C. and Hodges, C. V.: Studies 
on prostatic cancer I. The effect of castration, of estrogen and androgen injection on serum phosphatases in metastatic carcinoma. Cancer Res., 1, 293-297, 1941.

12) Cook, J. W., Hieger, I., Kennaway, E. L. and MAYNeORD, W. V.: Cancer production by pure hydrocarbones. Proc. Roy. Soc., 111, 455-484, 1932.

13) Cook, J.W., Kennaway, E.L. and KennaWAY, N.M. : Production of tumors in mice by deoxycholic acid. Nature, 145, 627, 1940, London.

14) Ochial, E., IchiKawa, M. and SaI, Z. : Nitroaction of 4-nitroquinoline- $\mathrm{N}$-oxide. J. Pharm. Soc. Nippon, 63, 280-282, 1943.

15) Nakahara, W, Fukuoka, F. and Sugimura, T. : Carcinogenic action of 4-nitroquinoline-N-oxide. Gann, 48, 129-137, 1957.

16) Mori, K. : Preliminary note on adenocarcinoma of the lung in mice induced with 4-nitroquinoline-N-oxide. Gann, 52, 265$270,1961$.

17) Horning, E.S.: The effects of castration and stielbestrol on prostatic tumors in mice. Brit. J. Cancer, 3, 211-230, 1949.

18) Horning, E. S. and Dmochowski, L. : Induction of prostate tumors in mice. Brit. J. Cancer, 1, 59-63, 1947.

19) Arthur, J. W. and Eastlick, H. L.: The relationship between dose and carcinogenic response obtained by injecting methylcholanthrene into the peritoneal cavity of chickens. Growth, 27, 199-204, 1963.

20) Severi, L., Squartini, F. and Olivi, M. : Tumor induction methylcholanthrene in mice: sites of tumor growth as related to the carcinogen dose and to endogenous hormonal stimulation. Acta Un. Int. Cancer, 18, 25-29, 1962.

21) Matake, H. and Imai, T.: Contribution on the development and growth of the benzpyrene skin cancer in mice. Gann, 49, 156-157, 1958.

22) Haddow, A. : Chemical carcinogens and their modes of action. Brit. Med. Bull., 14, 79-92, 1958.

23) Vasiliev, J. M. and Guelstein, V. I. :
Sensitivity of normal carcinogenic substances. J. Nat. Cancer Inst., 31, 1123$1151,1963$.

24) Hieger, I. : Carcinogenesis, 1961. London.

25) ORR, J.W.: The mechanism of chemical carcinogenesis, with particular reference to the time of development of irreversible changes in the epithelial cells. Brit. Med. Bull., 14, 99-101, 1958.

26) Bun-Hoi, N.P.: The role of experimental chemical carcinogenesis in research on the etiology of tumors. Arzneimittelforsch, $11,813-819,1961$.

27) RoHL, L. : Hormone dependency of prostatic cancer studies by cell-culture technique. Brit. J. Urol., 30, 450-453, 1958.

28) ZAHLER, H.: Die Auffrischung greisenhafter Hunde mittles Hodenirkstoffen und ihre Auswirkung and Hoden und Prostata. Virchows Arch. f. Path. Anat, 305, 65$107,1939$.

29) Zuckerman, S. and Sandys, O.C. : Further observation on effects of sex hormones on prostate and seminal vesicles of monkeys. J. Anat., 73, 597-616, 1939.

30) Wojewski, A. and LAska, A.: Experimental cancer of the prostate. Urol. int., 17, 223-229, 1964.

31) Farnsworth, W.E. : A possible mechanism of regulation of rat prostate function by testosterone. Biochim. Biophys. Acta, 150, 446-451, 1958.

32) Shida, K., Shimazaki, J., Urano, E., KURIHARA, H., TAKAhashi, H., FurUya, N. and TAYA, M. : Studies on mechanism of the action of androgens on prostate; Reduction and its role on the action of testrosterone to prostate. Jap. J. Urol, 63, 14-26, 1971.

33) Willis, R. A. : Pathology of tumors, $3 \mathrm{rd}$ ed. pp. 589-599, 1960, Butterworths, London.

34) Онота, K. : Precancer. The Saishin-Igaku, 13, 2-6, 1958, Saishin-Igakusha, Japan.

35) Rous, P. and KIDD, J.G. : Conditional neoplasms and subthreshold neoplastic states : A study of the tar tumors of rabbits. J. Exp. Med., 73, 365-390, 1941. 